\title{
The Importance of Using Hashtags on Raising Awareness about Social Issues
}

\author{
Issam Mostafa Ta'amneh (corresponding author) \\ Associate Professor \\ English Language \& Translation Department \\ Isra University, Jordan
}

\author{
Abeer Al-Ghazo \\ Associate Professor \\ Department of English Language and Literature \\ Ajloun National University, Jordan \\ Email:dr.taamneh.dr.alghazo@gmail.com
}

Received: September 15, 2021 Accepted: October 14, 2021 Published: October 28, 2021

doi:10.5296/ijld.v11i4.19139

URL: https://doi.org/10.5296/ijld.v11i4.19139

\begin{abstract}
Hashtags are a great way for people to search for topics on social networks that have a common theme. This study tried to explore the importance and power of hashtags that have gained popularity, on raising awareness about social issues. 252 participants (118 males and 134 females) participated in this study. In order to collect data, a questionnaire survey was used. The final questionnaire consisted of 20 items. It was a 4-point Likert scale: (1) Strongly disagree, (2) Disagree, (3) Agree, (4) Strongly agree. Means, standard deviations, a t-test and degrees were scored to analyze the participants' responses to the items of questionnaire. The results revealed that the overall degree of the expected benefits of using hashtags on raising the awareness about social events was high. Moreover, the results also revealed that there were no statistically significant differences, regarding gender (male and female).
\end{abstract}

Keywords: Hashtags, awareness, social issues

\section{Introduction}

In recent years, technology has become a crucial part of human lives as the whole world has 
become a small village due to the development in technology. Our world is moving towards progress in every step of life and because of that, we cannot deny that all are bounded with the loads of social problems and events such as poverty, crime, health problems, violence, corruption, suppression of human rights, discrimination, etc. Media is the most powerful tool of communication in increasing public awareness, collecting information, presenting people's points of views, perspectives, and attitudes towards a certain issue.

The core idea of social media is defined as "information content created by people using highly accessible and scalable publishing technologies that is intended to facilitate communications, and interaction with peers and public audiences, typically via the internet and mobile communications networks." (Wikipedia, 2009).

Many authors prove that the use of social media sites play several significant roles in all domains of our lives such as sharing ideas and suggestions between people, generating content like comments, digital videos and photos, and messages (Obar et al., 2015). So it can be said that social media sites are interactive internet-based applications because without the media, people in societies would be isolated from the rest of the world. Social networking sites take many different forms including content-sharing, relationship-building applications and social networking sites such as YouTube, Wikipedia, blogs, Twitter, Facebook, and LinkedIn.

Therefore, the emergence of these social networking sites plays an essential role for communication, assessing information easily and utilizing this information to their personal behavior and professional work. Mohsin (2019) stated that social networking sites have dominated the field of social networking since its creation in 2014and it is not only a social networking site for many people but it has become an interactive application and as a lifestyle. It should be emphasized that social networking sites have played an essential role in all fields of life. It is the best tool to spread awareness in all domains of our lives either they are political, social, educational, health or economic. It also gives us the latest sight about what is happening around us, make us aware about our rights, create awareness against evils and crimes in our society, share interests and activities with others and collect the views, information and attitudes toward certain issues.

The rise of social networking sites has influenced the way people live and communicate. (Ahmed et al., 2016). In the last years, the phenomenon of using the hashtag has emerged as a preferred tactic for many political and social changes around the world via social media. Therefore, the use of the hashtag has achieved a widespread use among internet users for emergency and crisis response. In hashtag movement, which is words or phrases preceded by a hash sign (\#) and used in popular social media such as Facebook, Twitter, Instagram, and YouTube, people use hashtags to share information and to identify messages on a specific topic like human right abuses, environmental and natural problems, or economic and political conflicts (Beirut, 2009). Yang (2016, p. 13) stated that "one of the most interesting developments in digital activism in recent years is the rise of hashtag activism, meaning discursive protest on social media united through a hash tagged word, phrase or sentence".

The history of the hashtag goes back to 2007 when Twitter user Chris Messina offered the 
sign \# in his tweet as a way to organize messages into meaningful groups. Since then, hashtag has been used on social networking sites. We cannot deny that the main purpose of using hashtag (\#) is to facilitate the duty of identifying messages that have a specific topic, share content related to the event and initiate conversation with speakers. Müller-Prove (2008) stated that hashtags now have become a regular phenomenon and they are widely used to convey messages to build public opinions and awareness. It is an essential way to show support for social and political issues. It is also a way to expand the usage of communication and make it democratic in a way that everyone has a way to express their opinions. Hashtags allow people to find posts that are relevant to their interests and interact with other social media users who share those interests by joining the conversation about hashtag (Jenna Mac Donald, 2017).

As we have mentioned above that hashtag is not a new trend on social media anymore. The hashtag activism is one of crucial ways to attract the attention and create awareness that is created for many important themes and topics. Here are many notable examples, \#KONY2012 (March 2012) ...\#BlackLivesMatter (July 2013) ...\#BringBackOurGirls (April 2014) ...\#YesAllWomen (May2014) ...\#IceBucketChallenge (July 2014) ...\#WhyIStayed (September 2014) ...\#ShoutYourAbortion (September 2015) ...\#IStandWithAhmed (September 2015) \#MeToo 2017) \#NeverAgain(2018) \#Coronavirus + \#COVID19 (2020). In fact, the hashtag activism is considered to be one of the popular approaches and methods that has a significant impact on political and social changes around the world. The growth of the hashtag movement could be attributed to the rise in the numbers of several social media platforms and growth of active users from different countries nowadays (Goswami,M,2018). In the current paper, the importance, power and effect of using hashtags on raising awareness about social events and general issues happened in the world will be investigated.

\subsection{Purpose of the Study}

Social media via a hash tagged word, phrase or sentence has a significant impact on many essential issues. It is considered as one of the most remarkable ways to get involved in social and political events. This study tried to explore the importance of hashtags which has gained popularity, on raising awareness about social and political events. The study aims to answer the following questions:

1)-What are the expected benefits of using hashtags on raising the awareness about social events?

2)- Are there any significant differences between male and female due to the hashtags practices and approaches used in social network sites?

\subsection{Significance of the Study}

The significance of the study stems from the great role of hashtags' effectiveness on conveying messages to build public opinions and awareness toward different issues such as social, political, environmental ones. 


\subsection{Statement of the Problem}

In recent years, many researchers study the importance and the influence of using the social media sites in general and hashtags in particular to enhance and increase the awareness toward different events in the world. Thus, people will be given the opportunity to communicate immediately with each other and share ideas and suggestions. Moreover, many studies revealed that there is a clear and positive correlation between people's perspectives towards using hashtags and their role on understanding the issues around us. Jackson and Welles (2015) indicated that hashtags have a major role on the development of social and political movements. Ibid (2015) stated that hashtags have also contributed to the spread of relations campaigns. So, we notice that using hashtags becomes as a functional mean to spread content and give an opportunity to communicate with others in order to raise the awareness towards socio-political changes across the world.

\section{Review of Literature}

Recently, many studies and researches have focused on the major role of using the social media sites in general and hashtags in particular. Alwagait, Shahzad, and Alim (2014) investigate the effect of excessive social media use on academic performance on universities students in Saudi Arabia. In order to recognize social media platform popularity, surveys were collected from 108 students. The results showed that there was not any relationship between social media usage in a week and GPA score. Moreover, the results pointed out that students looked at time management as a major factor that affected students' studies negatively.

Zhang, et al. (2017) indicate that female users prefer to use emotional and optimistic hashtag definitions more than male users. This research also shows a strong connection between the amount of hashtags used and the number of followers as well as the number of likes. The results show that greater male and female tweeters use somewhat similar vocabulary in their messages, but strong variations have been found in the usage of hashtags and usernames, in female tweeters citing significantly more programs and organizations with a persuaded attitude towards human activity effect on climate change, while male tweeters discuss considerably more private individuals and user's skeptical mentality.

Golbeck, J. et al. (2017) investigate why people were reading and using these hashtags and what impact it had on them. To conduct the study, a questionnaire, which contained multiple choice and free response questions, was administered to 83 people who had read or used these hashtags. The results revealed that the hashtags ended up serving as an ad hoc online community in which participants found a space of social support. Moreover, the findings pointed that building an improved sense of awareness was also an essential reason for and outcome of participation.

George, D. et al (2018) assess the characteristics of hashtag campaigns related to health in social media and compare three different campaigns in three commonly used social media platforms, namely, Twitter, Instagram, and Facebook. The campaigns were \#let's talk (World Health day2017), Hands up \#HIV prevention (World AIDS day 2016), and \#No tobacco 
(World No Tobacco Day2017). Public posts related to each were searched from three platforms and assessed separately. Source, publicity, credibility, reach outs, and other characteristics were assessed among each campaign and comparison was also done among the three social media. The results revealed that out of 812 posts, $507(62.4 \%)$ were related to the study. Facebook posts were more related (67.33\%), popular $(45.05 \%)$, and authenticated (28.22\%). Among the campaigns, \# let's talk was more credible $(96.33 \%)$ and authenticated (33.94\%). Moreover, 57.79\% from individual source and 79.82\% were awareness related.

Goswami, M (2018) indicates that the hashtag movement has proved to be a stimulating factor due to get entangled in socio-political events. He also indicates that the hashtag activism has emerged as a knowledge tag in advocating for a cause, connecting the social media users to participate and voice for a campaign across platforms through a concisely designed message. The researcher focused on a specific hashtag campaign called \#Kony2012 .

Philipp, Pavica Sheldon and Herzfeldt (2019) confirm that hashtag plays a powerful role as integral element of communication via social media. The researchers present six empirical studies in order to assess motivations for using hashtags. The results revealed that there are 10 different motivations for using hashtags: amusing, organizing, designing, conforming, trend gaging, bonding, inspiring, reaching, summarizing, and endorsing. Moreover, they show that there is a relationship between these 10 motivations and the different patterns of social media behavior.

Anke, Lina and Sandra (2020) combine a recently developed automated network analysis method and content analysis to analyze two Twitter debates about animal welfare issues. Our results show that among Twitter users, citizens and environmental organizations formed a common cluster whereas media actors formed their own sub-clusters in both debates. The findings emphasize the central role of citizens for the configuration of digital counter publics. The proposed approach can be further adapted and applied more widely for the analysis of online activism and debates.

Kouzy, et al. (2020) analyze the amount of misinformation that is posted on Twitter which related to the coronavirus epidemic. They searched Twitter with 14 popular hashtags and keywords related to the COVID-19 epidemic such as (\#Corona, \#Coronavirus, and \#COVID19). Then they have summarized and evaluated the individual tweets looking for the wrong information compared to the verified and revised resources. Descriptive statistics have been used to compare hashtags and terms, to identify individual tweets and account properties. The study included a total of 673 tweets. Most of the tweets were posted by informal individuals/groups (66\%), and $129(19.2 \%)$ belonged to verified Twitter accounts. The majority of the tweets included contained dangerous content $(91.2 \%) ; 548$ tweets with $81.4 \%$ included actual information related to the COVID-19 epidemic. About $70 \%$ of the tweets processed medical/public health information, whilst others were related to financial, social, and political factors. In total, 153 tweets at percentage of $24.8 \%$ contained false information, and 107 (17.4\%) included unconfirmed information related to the COVID-19 epidemic. 


\section{Methodology of the Study}

This section deals with the research methodology and procedures. It includes the different aspects of research methodology; the participants of the study, data collection, the research instrument and its validity and reliability, and appropriate statistical analysis.

\subsection{Participants of the Study}

The sample of the study consisted of 252 participants (118 males and 134 females). The range of their ages was 20 to 40 .

Table 1. Age of Participants

\begin{tabular}{lll}
\hline Age & Frequency & Percent \\
\hline $\mathbf{2 0}-\mathbf{2 5}$ & 42 & $16.6 \%$ \\
$\mathbf{2 5}-\mathbf{3 0}$ & 100 & $39.6 \%$ \\
$\mathbf{3 0}-\mathbf{3 5}$ & 90 & $35.7 \%$ \\
$\mathbf{3 5 - 4 0}$ & 20 & 7.9 \\
Total & 252 & $100 \%$ \\
\hline
\end{tabular}

As it can be seen from Table 1 above, most of the participants were between the ages of $25-30$ years (39.6\%), 35.7\% of them were between the ages of $30-35$ years, $16.6 \%$ of them were between the ages of 20-25 years. This showed that there is a wide usage of hashtags among youth in Jordan.

\subsection{Instrument of the Study}

In this study, the researchers used quantitative research (Analytical Descriptive Approach). A questionnaire survey is developed in order to answer the study questions by investigating the degree of the impact of using hashtags as a tool on raising awareness toward general issues. The final questionnaire consisted of 20 items. It was a 4-point Likert scale: (1) Strongly disagree, (2) Disagree, (3), Agree (4) Strongly agree.

\subsubsection{Validity of the Instrument}

In order to check the validity of the questionnaire (checking if it measures what is it meant to measure), the researchers submit it to a group of specialists. Three faculty members with $\mathrm{PhDs}$ at the Department of English Language and Literature and the department of information technology at Ajloun National University, three experienced teachers at Ajloun Educational Directorate. The researchers took the suggested modifications into consideration to build the suitable questionnaire that achieves the purpose of the study. 


\section{Macrothink}

International Journal of Learning and Development

ISSN 2164-4063 2021, Vol. 11, No. 4

\subsubsection{Reliability of the Questionnaire}

Cronbach's alpha coefficients was used to find the reliability of the questionnaire. Table 2 shows the reliability score, which was under 1.0, hence acceptable:

Table 2. Reliability Statistics

Cronbach's Alpha $\quad$ N of Items

\subsubsection{Statistical Analysis}

In this study, the Statistical Package for Social Scientifics (SPSS) will be used. Means, standard deviations, a t-test and agreement degrees were computed to summarize the participants' responses to the items of the questionnaire. For data analysis, the researchers used the following scale:

\begin{tabular}{lll}
\hline Low & $\mathbf{1}$ & $\mathbf{1}-\mathbf{2 . 3 3}$ \\
\hline Moderate & 2 & $2.34-3.66$ \\
High & 3 & $3.67-5$ \\
\hline
\end{tabular}

\section{Results and Discussion}

\subsection{Results Related to the First Question}

The first question asks about the expected benefits of using hashtags on raising the awareness about social events. In order to answer this question, the researchers calculated the means, standard deviations and the degree for each item and the overall score of the questionnaire as shown in table (3). 
Table 3. Means and Standard Deviations of the Main Benefits of Using Hashtags on Raising the Awareness about Social Events

No Items Mean $\begin{array}{lll}\text { Standard } & \begin{array}{l}\text { Agreement } \\ \text { Degree }\end{array}\end{array}$

I think that hashtag has been growing as a

1 popular approach to get involved is social $4.43 \quad 0.93 \quad$ High and political events.

I believe that using hashtags has been

2 emerged as a remarkable method to promote $4.24 \quad 0.94 \quad$ High participatory behavior.

I think that using hashtags organizes public discussion.

$4.14 \quad 1.06 \quad$ High

I think that using hashtags share ideas and

4 suggestions between people, generate $4.24 \quad 0.89 \quad$ High content like comments.

I think that hashtag is the best tool to spread

5 awareness in the modern society either it is political, social, educational, health or $3.90 \quad 1.14 \quad$ High economic ones.

I think that hashtag also gives us latest sight about what is happening around us.

$4.24 \quad 0.89$

High

I think that hashtag makes us aware about

7 our rights, create awareness against evils an $4.00 \quad 1.14$ High crimes in our society,

I think that hashtag shares interests and

8 activities with others and collect the views, information and attitudes toward certain $3.95 \quad 1.07$ High issue.

I think that hashtag shares content related to

9 the event and initiate conversation wit $\begin{array}{ll}4.24 & 0.94\end{array}$ High speakers

10 I think that hashtag is widely used to $3.90 \quad 0.94$ High 
convey message to build public opinion and awareness.

I think that hashtag increases your visibility

11 online, making your posts reach a broader audience

$\begin{array}{lll}4.00 & 1.22 \quad \text { High }\end{array}$

I think that Hashtags help increase your

12 business' social media presence by making your content viewable to anyone

$\begin{array}{lll}4.10 & 1.09 \quad \text { High }\end{array}$

13 I don't think that hashtag is the best tool to 1.86 spread awareness in the modern society.

14 I think that using Hashtags makes finding information easier for social media users

$4.10 \quad 1.14$

High

Hashtags are the simplest way to organize

15 the endless amount of information posted to social media so that you're only seeing what

3.90 $0.89 \quad$ High
you find relevant

I think that hashtag is able to join a bigger

16 conversation, and connect with others on that topic.

\section{$\begin{array}{llll}\text { I think that hashtag stimulates other people's } & 4.35 & .58 & \text { High }\end{array}$}

17 attitudes and perceptions towards what I want to express with my postings.

I think that hashtag is not used to spread a $3.25 \quad .63$ message to a certain class of people.

I don't think that hashtag has an essential

1.99

Low

19 effect to change people's views toward many socio-political issues.
I don't convince of using hashtags as an
2.73
.55
Moderate

20 important way to share ideas and information 


\section{Ml Macrothink}

Table 3 shows that item (1) "I think that hashtag has been growing as a popular approach to get involved is social and political events." receives the highest mean (4.43) regarding the degree of agreement, followed by item (17) "I think that hashtag stimulates other people's attitudes and perceptions towards what I want to express with my postings." which comes in the second rank with a mean (4.35). The table shows that statements number (2),(4),(6) and (9): "I believe that using hashtags has been emerged as a remarkable method to promote participatory behavior."," I think that using hashtags share ideas and suggestions between people, generate content like comments.", "I think that hashtag also gives us latest sight about what is happening around us.", and "I think that hashtag shares content related to the event and initiate conversation with speakers" come in the third rank with a mean (4.24). Item (13)was ranked last with a mean (1.86). This table also shows that the total mean as a whole is (3.74).

This shows that that the overall degree of the expected benefits of using hashtags on raising the awareness about social events was high with a mean of 3.74 which is considered high. This result highlights the importance of using hashtags as essential tools to build public opinion and awareness about what is happening around us either it is political, social, educational, health or economic issue. Accordingly, the results of this study agreed with the result of the study of Golbeck, J et al (2017) who investigated why people were reading and using these hashtags and what impact it had on them. The results revealed that the hashtags ended up serving as an ad hoc online community in which participants found a space of social support. Moreover, they showed that building an improved sense of awareness was also an essential reason for and outcome of participation.

\subsection{Results of the Second Question}

The second question asks about if there are any significant differences between male and female due to the hashtags practices and approaches used in social network sites. To clear-out if those differences were statistically significant Paired Samples Test were run. Table (4) shows the results:

\section{Group Statistics}

\begin{tabular}{|ll|l|l|l|l|}
\hline & & & & & $\begin{array}{l}\text { Std. } \\
\text { Std. } \\
\text { Deviar } \\
\text { Mean }\end{array}$ \\
\hline $\mathrm{q} 1$ & Male & 118 & 3.76 & .214 & .066 \\
& Female & 234 & 3.73 & .224 & .047 \\
\hline
\end{tabular}




\section{Independent Samples Test}

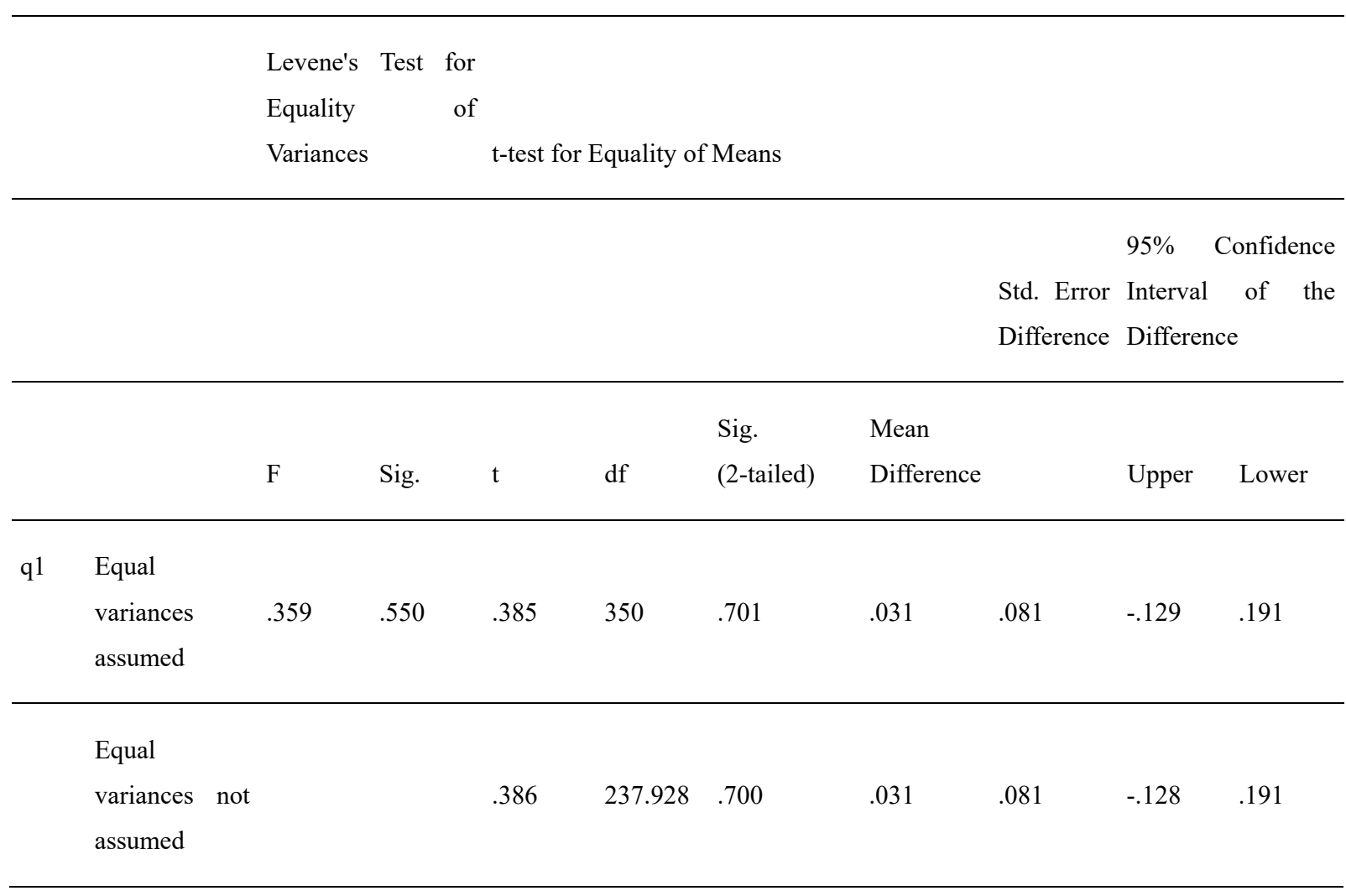

The means of the two groups were approximately equal in using hashtags practices and approaches in social network sites. It can be concluded that there were no statistically significant differences at (0.05) attributed to the variable of gender (male and female). This might be due to the fact that all males and females have interests on using hashtags to spread a message to a specific audience of people, to share the news and ideas with the largest number of other people, increase the followers on specific issue and stimulates other people's thinking about what you want to express with these postings. Accordingly, the results of this study were inconsistent with the study of Zhang Ye (2017) who indicated that females users prefer using hashtags more than males.

\section{Conclusion}

This study attempted to highlight the importance and power of hashtags which have gained popularity, on raising awareness about social events. The findings of this study revealed that the overall degree of the expected benefits of using hashtags on raising the awareness about social events was high with a mean of 3.74. Moreover, the results showed that there were no statistically significant differences attributed to gender (male and female) in using hashtags practices and approaches in social network sites. Most people are aware of the importance of Hashtags as a powerful tool of communication in increasing the public awareness and collecting information, the points of views, perspectives and attitudes toward certain issue. 


\subsection{Recommendations}

In light of the results of the study and to gain a deeper fruitful understanding of the impact of using hashtags as a powerful tool of communication in increasing the public awareness, the researchers present the following recommendations:

1-More comprehensive studies must be conducted to gain a deeper understanding of the impact of hashtag used on different social networking sites.

2-Other comprehensive studies must be conducted to identify the factors or obstacles that may hinder the effective transfer of the received information through hashtags.

\section{References}

Ahmed, S., Jaidka, K., \& Cho, J. (2016). Tweeting India's Nirbhaya protest: a study of emotional dynamics in an online social movement. Social Movement Studies, 1-19. https://doi.org/10.1080/14742837.2016.1192457

Alwagait, E., Shahzad, B., \& Alim, S. (2014). Impact of social media usage on students' academic performance in Saudi Arabia. Computers in Human Behavior, 51(Part B), 1092-1097. https://doi.org/10.1016/j.chb.2014.09.028

Wonneberger, A., Hellsten, I. R., \& Jacobs, S. H. (2021). Hashtag activism and the configuration of counterpublics: Dutch animal welfare debates on Twitter. Information, $\begin{array}{llll}\text { Communication } \quad \& \quad \text { Society, } & \text { 24(12), }\end{array}$ https://doi.org/10.1080/1369118X.2020.1720770

Beirut. (2009). Why do people really tweet? The psychology behindtweeting! Thought Pick. Retrieved December 2020, from http://blog.thoughtpick.com/2009/08/ why-do-people-really-tweet-the-psychologybehindtweeting.html

George, N., Britto, D. R., Krishnan, V., Dass, L. M., Prasant, H. A., \& Aravindhan, V. (2018). Assessment of hashtag (\#) campaigns aimed at health awareness in social media. Journal of education and health promotion, 7. https://doi.org/10.4103/jehp.jehp_37_18

Golbeck, J., Ashktorab, Z., Banjo, R. O., Berlinger, A., Bhagwan, S., Buntain, C., ... \& Wu, D. M. (2017, June). A large labeled corpus for online harassment research. In Proceedings of the 2017 on web science conference (pp. 229-233). https://doi.org/10.1145/3091478.3091509

Goswami, M. (2018). Social Media and Hashtag Activism. Retrieved December 2020, from file://C:/Users/user/Downloads/SocialMediaandHashtagActivism\%20(2).pdf

Jackson, S. J., \& Foucault Welles, B. (2015). Hijacking \# myNYPD: Socialmedia dissent and networked counterpublics. Journal of Communication, (65), 932-952. https://doi.org/10.1111/jcom.12185

Kouzy, R., Abi Jaoude, J., Kraitem, A., El Alam, M. B., Karam, B., Adib, E., ... \& Baddour, K. (2020). Coronavirus goes viral: quantifying the COVID-19 misinformation epidemic on Twitter. Cureus, 12(3). https://doi.org/10.7759/cureus.7255 


\section{Macrothink}

International Journal of Learning and Development

ISSN 2164-4063 2021, Vol. 11, No. 4

Mac Donald, J. (2017). The Importance of hashtags: Know where, why, and how to use them. Retreived from https://www.business2community.com/socialmedia/importance-hashtagsknow-use-01837644/amp

Mohsin, M. (2019). Facebook Stats Every Marketer Should Know in 2020. Retrieved December 2020, from https://www.oberlo.com.

Muller-Prove, M. (2008), "Modell und Anwendungperspektive des Social Tagging," Chapter 2 of Birgit Gaiser, Thorsten Hampel and Stephanie Panke (Eds.), Good Tags - Bad tags. Social Tagging in der Wissensorganisation. Waxmann: Berlin

Obar, J. A., \& Wildman, S. S. (2015). Social media definition and the governance challenge-an introduction to the special issue. Obar, JA and Wildman, S.(2015). Social media definition and the governance challenge: An introduction to the special issue. Telecommunications policy, 39(9), 745-750. https://doi.org/10.2139/ssrn.2647377

Rauschnabel, P. A., Sheldon, P., \& Herzfeldt, E. (2019). What motivates users to hashtag on social media?. Psychology \& Marketing, 36(5), 473-488. https://doi.org/10.1002/mar.21191

Yang, G. (2016). Narrative agency in hashtag activism: The case of\# BlackLivesMatter. Media and communication, 4(4), 13. https://doi.org/10.17645/mac.v4i4.692

Ye, Z., Hashim, N. H., Baghirov, F., \& Murphy, J. (2018). Gender differences in Instagram hashtag use. Journal of Hospitality Marketing \& Management, 27(4), 386-404. https://doi.org/10.1080/19368623.2018.1382415 


\section{Appendix A}

\begin{tabular}{|c|c|c|c|c|c|}
\hline No. & Statements & $\begin{array}{l}\text { Totally } \\
\text { Agree }\end{array}$ & Agree & Disagree & $\begin{array}{c}\text { Totally } \\
\text { Disagree }\end{array}$ \\
\hline 1 & $\begin{array}{l}\text { I think that hashtag has been growing as a popular } \\
\text { approach to get involved is social and political events. }\end{array}$ & & & & \\
\hline 2 & $\begin{array}{l}\text { I believe that using hashtags has been emerged as a } \\
\text { remarkable method to promote participatory behavior. }\end{array}$ & & & & \\
\hline 3 & I think that using hashtag organizes public discussion. & & & & \\
\hline 4 & $\begin{array}{l}\text { I think that using hashtags share ideas and suggestions } \\
\text { between people, generate content like comments. }\end{array}$ & & & & \\
\hline 5 & $\begin{array}{l}\text { I think that hashtag is the best tool to spread awareness in } \\
\text { the modern society either it is political, social, } \\
\text { educational, health or economic ones }\end{array}$ & & & & \\
\hline 6 & $\begin{array}{l}\text { I think that hashtag also gives us latest sight about what is } \\
\text { happening around us. }\end{array}$ & & & & \\
\hline 7 & $\begin{array}{l}\text { I think that hashtag makes us aware about our rights, } \\
\text { create awareness against evils and crimes in our society. }\end{array}$ & & & & \\
\hline 8 & $\begin{array}{l}\text { I think that hashtag shares interests and activities with } \\
\text { others and collect the views, information and attitudes } \\
\text { toward certain issue. }\end{array}$ & & & & \\
\hline 9 & $\begin{array}{l}\text { I think that hashtag shares content related to the event and } \\
\text { initiate conversation with speakers. }\end{array}$ & & & & \\
\hline 10 & $\begin{array}{l}\text { I think that hashtag is widely used to convey message to } \\
\text { build public opinion and awareness. }\end{array}$ & & & & \\
\hline 11 & $\begin{array}{l}\text { I think that hashtag increases your visibility online, } \\
\text { making your posts reach a broader audience. }\end{array}$ & & & & \\
\hline 12 & $\begin{array}{l}\text { I think that Hashtags help increase your business' social } \\
\text { media presence by making your content viewable to } \\
\text { anyone. }\end{array}$ & & & & \\
\hline 13 & $\begin{array}{l}\text { I don't think that hashtag is the best tool to spread } \\
\text { awareness in the modern society. }\end{array}$ & & & & \\
\hline 14 & $\begin{array}{l}\text { I think that using Hashtags makes finding information } \\
\text { easier for social media users. }\end{array}$ & & & & \\
\hline 15 & $\begin{array}{l}\text { Hashtags are the simplest way to organize the endless } \\
\text { amount of information posted to social media so that } \\
\text { you're only seeing what you find relevant. }\end{array}$ & & & & \\
\hline 16 & $\begin{array}{l}\text { I think that hashtag is able to join a bigger conversation, } \\
\text { and connect with others on that topic. }\end{array}$ & & & & \\
\hline 17 & $\begin{array}{l}\text { I think that hashtag stimulates other people's attitudes and } \\
\text { perceptions towards what I want to express with my } \\
\text { postings. }\end{array}$ & & & & \\
\hline 18 & $\begin{array}{l}\text { I think that hashtag is not used to spread a message to a } \\
\text { certain class of people. }\end{array}$ & & & & \\
\hline 19 & $\begin{array}{l}\text { I don't think that hashtag has an essential effect to change } \\
\text { people's views toward many socio-political issues. }\end{array}$ & & & & \\
\hline 20 & $\begin{array}{l}\text { I think that hashtags do not have any role on } \\
\text { understanding what it happens today. }\end{array}$ & & & & \\
\hline
\end{tabular}




\section{Macrothink}

International Journal of Learning and Development

ISSN 2164-4063 2021, Vol. 11, No. 4

\section{Copyright Disclaimer}

Copyright for this article is retained by the author(s), with first publication rights granted to the journal.

This is an open-access article distributed under the terms and conditions of the Creative Commons Attribution license (http://creativecommons.org/licenses/by/4.0/). 